\title{
Feasibility of Distal Mechanical Thrombectomy in M3, A3 and P3 Segments via a 0.013-inch Delivery System: Preliminary Experience
}

\author{
Yilmaz ONAL¹, Murat VELIOGLU1', Ugur DEMIR', Erhan CELIKOGLU², Hakki M. KARAKAS'1 \\ ${ }^{1}$ Fatih Sultan Mehmet Training and Research Hospital, Department of Radiology, Istanbul, Turkey \\ ${ }^{2}$ Fatih Sultan Mehmet Training and Research Hospital, Department of Neurosurgery, Istanbul, Turkey \\ Corresponding author: Murat VELIOGLU muratvelix@yahoo.com
}

\section{ABSTRACT}

AIM: To assess the safety and efficacy of distal thrombectomy (DT) using a Catch View mini (CVm) device via a microcatheter with a 0.013-inch inner diameter.

MATERIAL and METHODS: Nine of 246 acute ischemic stroke patients who underwent mechanical thrombectomy developed distal emboli and were included in the study. In all nine subjects (mean age, 64.5 \pm 11.6 ; range, 39-77 years), a combination of CVm and a 0.013 -inch microcatheter was used in distal mechanical thrombectomy. Modified Thrombolysis in Cerebral Ischemia scores of $2 \mathrm{c}$ and 3 were considered to indicate successful recanalization, and patients with a Modified Rankin Score of $\leq 2$ on the 90th day were considered to have good clinical outcomes.

RESULTS: Eleven DT maneuvers were performed using the same stent retriever and microcatheter. The mean National Institutes of Health Stroke Scale score was $13 \pm 3.4$. Thrombectomy was performed from M3 in six patients, A3 in four, and P3 in one. Successful recanalization was achieved in all of the procedures. The rate of good clinical outcome was $55.5 \%$.

CONCLUSION: Advances in technology in the endovascular field enable access to more distal vessels in acute ischemic stroke. As the profile of the instruments used during access decreases, the risk of complications may decrease. The CVm stent retriever could become a useful tool in DT based on its compatibility with a 0.013-inch lumen delivery system.

KEYWORDS: Stroke, Distal thrombectomy, Mini stent retriever

ABBREVIATIONS: AIS: Acute ischemic stroke, DT: Distal thrombectomy, LVO: Large vessel occlusion, CVm: Catch View mini, mTICI: Modified Thrombolysis in Cerebral Ischemia, mRS: Modified Rankin Score, NIHSS: National Institutes of Health Stroke Scale, ADAPT: Direct aspiration first pass technique, SR: Stent retriever, MT: Mechanical thrombectomy, BGC: Balloon guide catheter

\section{INTRODUCTION}

$\Lambda$ cute ischemic stroke (AIS) is one of the major causes of death and disability (7). This is largely due to large vessel occlusion (LVO), resulting in extensive brain infarction. After five trials, the benefit of endovascular treatment in patients with LVO has been demonstrated to be clear, and endovascular treatment has become the cornerstone of AIS management in patients with LVO $(1,2,7,10,19)$. However, patients with tandem occlusions, posterior system strokes, and distal thrombectomies were not included in these studies. Distal embolization is a well-known entity, despite various techniques used to prevent thrombectomy in LVO, and it is associated with increased morbidity $(3,6)$. In addition,
Yilmaz ONAL (1) : 0000-0001-7703-141X Murat VELIOGLU (1) : 0000-0001-9384-2378 Ugur DEMIR (1) : 0000-0002-2500-7538
Erhan CELIKOGLU (10): 0000-0002-2064-9072

Hakki M. KARAKAS (D) : 0000-0002-1328-8520 
the successful recanalization rate and clinical outcome are closely related (18). In the literature, successful recanalization is indicated by a Modified Thrombolysis in Cerebral Ischemia (mTICl) score of $2 \mathrm{~b}-3$. However, there are studies showing that patients with $\mathrm{mTICI}$ scores of $2 \mathrm{c}$ and 3 have better clinical outcomes than patients with $\mathrm{mTICI}$ scores of $2 \mathrm{~b}(9,12)$. If $a 2 b$ recanalization is found, important questions to consider are whether primary or secondary distal emboli should be treated and how distal we should go.

Distal delivery of mini stent retrievers (SRs) is possible beyond the M2, A2, and P2 segments due to their compatibility with small-diameter microcatheters. In this study, we aimed to assess the feasibility of the new Catch View mini (CVm) SR (Catch View, Balt, Montmorency, France) delivered via a 0.013inch microcatheter (Headway duo 167 cm; MicroVention, Inc., Aliso Viejo, California, USA) at distal emboli developed during mechanical thrombectomy (MT) in patients with proximal LVO.

\section{MATERIAL and METHODS}

\section{Patient Population}

This study was approved by the scientific board, and informed consent was obtained from the patients' relatives (Date: 24.02.2020; No: 17073117-050.06-E.52). We performed a retrospective review of our interventional database records. We evaluated the patients' procedure reports, medical charts, and angiographic images. We recorded the patients' demographic characteristics, complaints, occlusion locations, technical, and clinical complications, recanalization rates, and clinical outcomes.

Our hospital is a comprehensive stroke center operating on a $24 / 7$ basis. The inclusion criteria for MT were LVO confirmed by computed tomography (CT) angiography or magnetic resonance (MR) angiography and a baseline National Institutes of Health Stroke Scale (NIHSS) score of $\geq 5$ upon admission. Intracranial hemorrhage was excluded using non-contrast-enhanced CT, and advanced parenchymal ischemic damage was excluded using magnetic resonance imaging. In addition, patients with an appropriate time frame and with no contraindications were administered intravenous (IV) tissue plasminogen activator (tPA). Patients who presented to our hospital were followed up in the neurology critical intensive care unit, and those referred from external centers were directed to the referring neurology clinic following treatment. All subjects underwent a control CT at the $24^{\text {th }}$ hour or earlier in case of neurological deterioration.

Nine of the 246 subjects who underwent MT between January 2019 and December 2019 were included in this study as they developed distal emboli. There were five men (55.6\%) and four women $(44.4 \%)$ with a mean age of $64.5 \pm 11.6$ years (range, 39-77 years). Eleven distal thrombectomies were performed in different locations. $\mathrm{mTICl}$ scores of $2 \mathrm{c}-3$ were considered to indicate successful recanalization, and a Modified Rankin Score (mRS) of $\leq 2$ on the $90^{\text {th }}$ day was considered a good clinical outcome.

\section{Endovascular Procedures}

All procedures except one were performed under local anesthesia. In one patient with basilar artery occlusion, the procedure was performed under general anesthesia (Figure 1AF). Our standard approach was to insert an $8 \mathrm{~F}$ introducer from the femoral artery. The technique to be used was determined according to the vascular anatomy in preoperative computed tomography angiography examination. A direct aspiration first pass technique (ADAPT) was used in four patients, and SR was used in five patients for LVO. In the ADAPT group, the initial setup was performed by positioning the Neuron MAX 90-cm sheath (Penumbra, Alameda, California, USA) in the most distal internal carotid artery (ICA). The Sofia 6F 115-cm device (MicroVention, Tustin, California, USA) was used as an aspiration catheter in all patients. The Sofia was navigated to the level of the occlusion with guidance from the microcatheter. Aspiration was then performed as described in the literature (11). A balloon guide catheter (BGC), the 8F Merci (Concentric Medical CA USA), was used in all the SR groups. Two types of SR were used for LVO (Catch Maxi, Balt, Montmorency, France; Solitaire Platinum, ev3, Irvine, CA, USA).

In the images taken after the first attempt, the proximal LVO was recanalized except in one patient. In a patient with carotid T occlusion, the clot advanced to the M1 level after the first pass, and recanalization was achieved after the second pass.

A CVm SR and Headway Duo 167-cm (0.013-inch) combination was used for DT in all procedures. CV is a new self-expandable and re-sheathable SR with a laser-cut closedcell design and compatibility with a smaller delivery system. It also has enhanced visibility due to platinum and tantalum markers impregnated into the stent profile.

DT was applied as follows (Figure 2A-C):

a) Deployment of the SR by centralizing the thrombus

b) Confirming the exact localization of the SR using contrast injection in an unsubtracted view

c) Partially re-sheathing the SR toward the proximal end of the clot to create better engagement during retrieval, thus avoiding fragmentation

d) Retrieving the SR microcatheter assembly under continuous aspiration.

Successful recanalization rates and adverse procedurerelated events were recorded. Hemorrhages were graded according to the method used in the European Cooperative Acute Stroke Trials (15).

\section{RESULTS}

The proposed definition of $\mathrm{M} 3$ is from the circular sulcus of the insula to the external/superior surface of the Sylvian fissure (5). For A3, it is from the origin of the callosomarginal artery to the artery's posterior turn above the corpus callosum (17). For P3, it is a segment within the quadrigeminal cistern (14). In this study, all of the patients who underwent DT had secondary emboli that developed during LVO intervention. Thrombectomy was performed from M3 in six patients, A3 in four, and P3 in one (Table I), and tPA was administered in $44.4 \%$ of patients. In all 11 DT maneuvers, recanalization 
Onal Y. et al: Distal Mechanical Thrombectomy

Table I: List of Initial Occlusion and Distal Embolism Localization with Recanalization Rates and Clinical Outcomes

\begin{tabular}{|c|c|c|c|c|c|c|}
\hline Patient No & Initial Occlusion & NIHSS Score & tPA & Distal Occlusion & Final TICI Score & mRS at $90^{\text {th }}$ Day \\
\hline 1 & Carotid T & 20 & + & A3, M3 & 3 & 6 \\
\hline 2 & M1 & 13 & + & M3 & 3 & 2 \\
\hline 4 & Tandem & 14 & + & A3 & $2 c$ & 4 \\
\hline 5 & Carotid T & 13 & - & M3 & $2 c$ & 3 \\
\hline 7 & Tandem & 15 & - & A3, M3 & $2 c$ & 2 \\
\hline 8 & ICA & 8 & - & M3 & 3 & 0 \\
\hline 9 & M1 & 10 & + & A3 & 3 & 1 \\
\hline
\end{tabular}

*GCS: Glasgow coma scale, NIHSS: National Institutes of Health stroke scale, tPA: Tissue plasminogen activator, TICl: Thrombolysis in cerebral infarction, $\boldsymbol{m R S}$ : Modified rankin score.
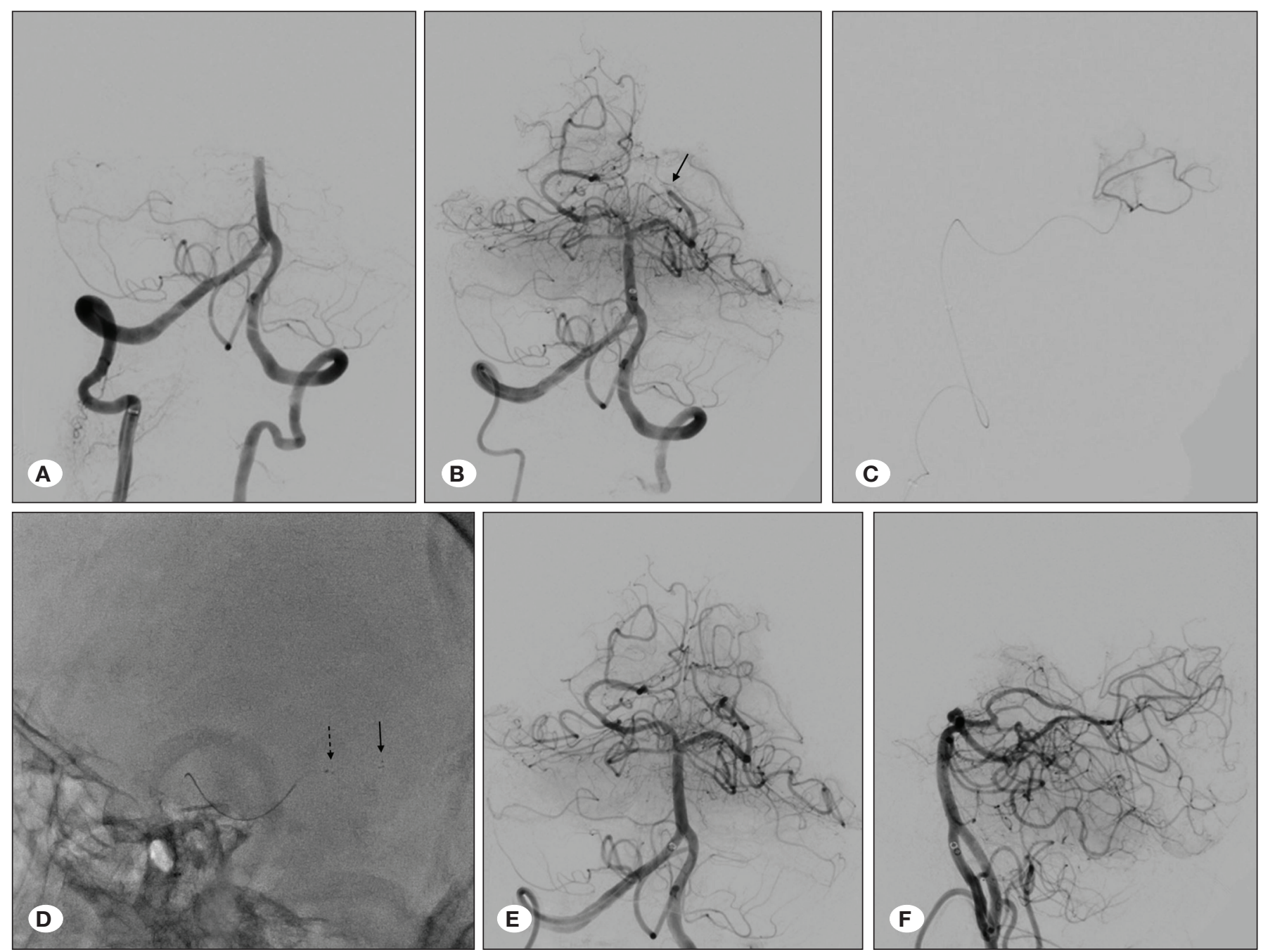

Figure 1: Procedural images of a 70-year-old woman with basilar artery occlusion. A) Right vertebral artery injection shows occlusion of the basilar artery. B) After the first pass with the ADAPT technique, while performing recanalization of the basilar artery, we observed a distal embolism in the left PCA (black arrow). C) Selective microcatheter injection after the occlusion was bypassed. D) CVm SR proximal (dashed arrow) and distal markers (black arrow) deployed to cover the clot. E) Anteroposterior (AP) and F) lateral control images show complete recanalization. ADAPT: direct aspiration first pass technique, PCA: posterior cerebral artery, CVm: Catch View mini, SR: stent retriever. 


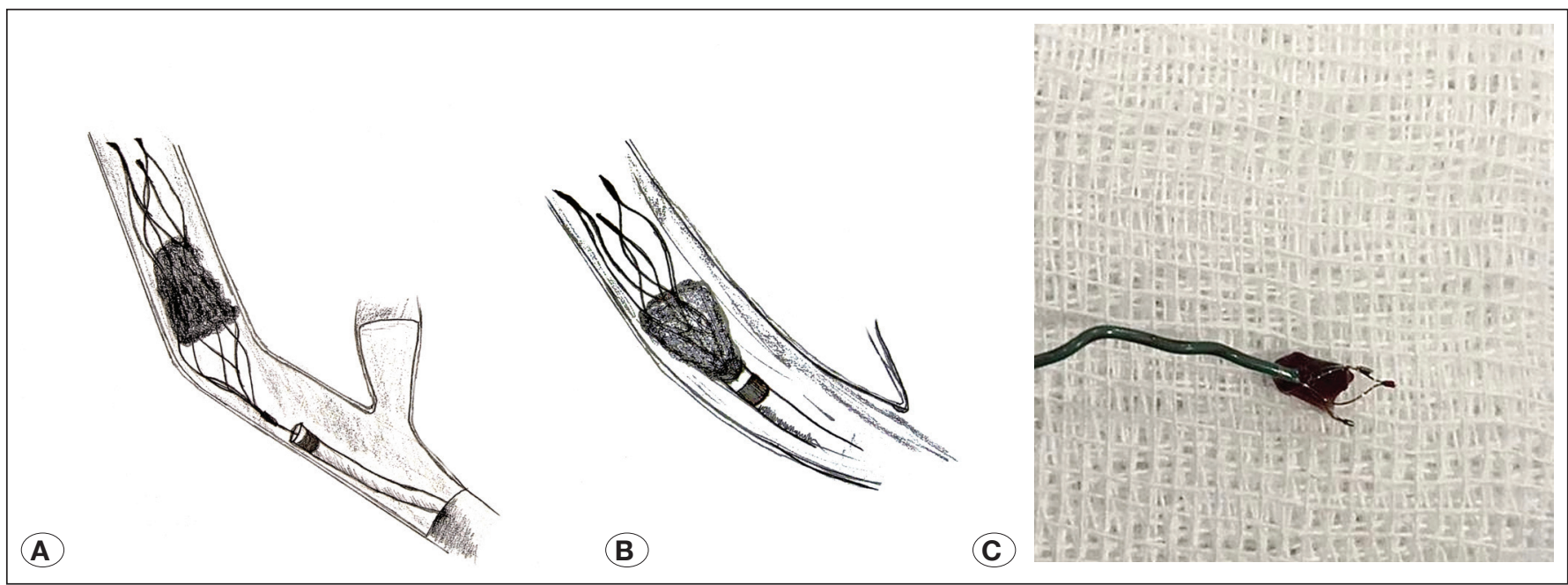

Figure 2: Illustration of the distal thrombectomy technique. A) The deployment of the stent retriever (SR) by centralization of the thrombus. B) Partial re-sheathing of the SR toward the proximal part of the clot to create better engagement. C) Image of a patient for whom distal thrombectomy was performed. The clot was compressed between the microcatheter and the stent to prevent re-fragmentation.

was achieved in the first pass. Successful recanalization was achieved in all procedures. After DT, no emboli were observed in the new territory.

One of the subjects had right ICA occlusion. The NIHSS score was 8 when the treatment decision was made, and the patient had crescendo ischemic attacks. The occlusion in the ICA was passed with the help of a microcathetermicroguidewire, and BGC was the initial setup in this patient. Selective microcatheter injection was used to assess whether we were in the true lumen and whether there were clots in the intracranial vessels. After observing that there were no clots in the intracranial vessels, the distal protection filter was positioned in the subpetrous segment (SpiderFX, ev3, Plymouth, Minnesota, USA). A carotid stent was deployed. There was a clot in the form of a filling defect in the filter on the control image. The filter was retrieved under BGC aspiration; however, upon observation of the M3 level occlusion on the control image, the clot at this level was removed with the combination of CVm 3.5x15 mm SR and Headway Duo 167 $\mathrm{cm}$ to provide complete recanalization.

In addition, periprocedural extravasation occurred in a patient with tandem occlusion. In this patient, BGC was the primary setup, and angioplasty was performed for the ICA occlusion. The middle cerebral artery (MCA) was then opened with SR. On the control image, it was observed that there was a distal embolism in the A3 segment, as well as extravasation of a small branch from the MCA upper trunk in the precentral area. The BGC was inflated to stop the flow, and the extravasation disappeared after a few minutes. DT from the A3 segment was performed, and $\mathrm{mTICI} 2 \mathrm{c}$ recanalization was obtained, as shown in the final control image (Figure 3A-F).

One patient developed symptomatic intracranial hemorrhage. This patient underwent thrombectomy from both the M3 and $A 3$ segments and had initially presented with carotid $T$ occlusion. Complete recanalization was achieved in the control image. Parenchymal hematoma type 2 was detected in the control CT, which was obtained early following neurological deterioration. A decompressive craniotomy was performed, but the patient died.

\section{DISCUSSION}

MT has become the standard of care in proximal LVO, yet it has not been incorporated into routine clinical practice for $\mathrm{M} 2$ and beyond due to insufficient data (16). The reported rates of distal embolization during LVO MT range from $0 \%$ to $12.5 \%$ in new arterial territories and up to $22.8 \%$ within the same territory (13). Due to their distal placement and smaller sizes, these vessels constitute a significant technical challenge and may carry a higher risk of complications. In addition, distal occlusions may respond better to tPA, leading to additional avoidance of the procedure (4). However, distal emboli that develop during a procedure for LVO are associated with increased morbidity (6). Studies have investigated the definition of successful recanalization rates. Kleine et al. studied 277 patients with MCA occlusion and subsequent successful recanalization. They compared 119 patients with $\mathrm{mTICl} 3$ recanalization with the $\mathrm{mTICl} 2 \mathrm{~b}$ group. They found that the mTICl 3 group had lower NIHSS scores during discharge and shorter hospital stays. They concluded that $\mathrm{mTICI} 3$ recanalization is a strong independent factor for neurological recovery $(\mathrm{OR}=4.3,95 \% \mathrm{Cl}$ 2.2 to $8.3, \mathrm{p}<0.001)$ and favorable NIHSS outcome $(\mathrm{OR}=3.0$, $95 \% \mathrm{Cl} 1.5$ to $6.3, \mathrm{p}=0.003$ ) (12). A meta-analysis published by Jang et al. analyzed 12 studies with 2084 subjects and demonstrated similar results. The authors pointed out that $\mathrm{mTICI} 2 \mathrm{c}(\mathrm{OR}=2.28,95 \% \mathrm{Cl} 1.65-3.13)$ and $3(\mathrm{OR}=2.40,95 \%$ Cl 1.74-3.30) were strongly related to good clinical outcomes compared with $2 \mathrm{~b}$ at the $90^{\text {th }}$ day, but they found no difference between $\mathrm{mTICl} 2 \mathrm{c}$ and $3(\mathrm{OR}=1.05,95 \% \mathrm{Cl} 0.76-1.46)(9)$. In the current study, which included patients with distal emboli, we considered successful recanalization to be indicated by $\mathrm{mTICl} 2 \mathrm{c}-3$. 

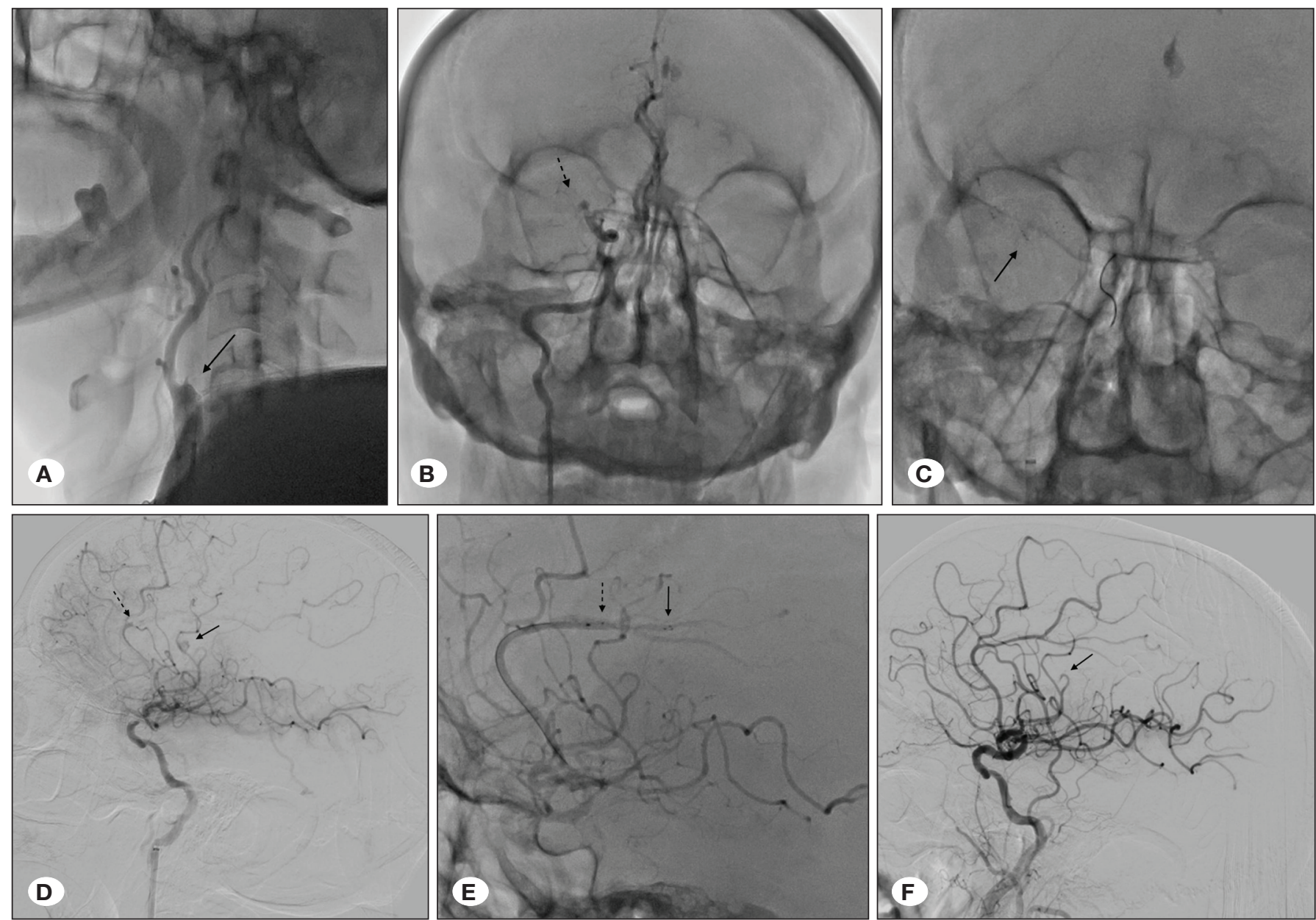

Figure 3: Procedural images of a 68-year-old male with a tandem occlusion and an NIHSS score of 14. A) Occlusion in the ICA (black arrow). B) After the occlusion in the ICA was passed with a 125-cm diagnostic catheter. The control image shows the occluded right M1 segment (dashed arrow). Navigation through the occluded ICA with the BGC was not possible. Therefore, angioplasty was performed first, and the occlusion was bypassed with the BGC thereafter. C) Solitaire SR (black arrow) was used for the occlusion in the M1 segment. D) In the control image taken after the first pass, there were distal emboli in the A3 segment (dashed arrow) and extravasation of a small branch from the MCA upper trunk in the precentral area (black arrow). The BGC was then inflated for a few minutes. E) After the extravasation disappeared, CVm SR (arrows) was used for the clot in the A3 segment. F) mTICl 2c recanalization was achieved, as shown in the final control image. The black arrow points to slow flow in the MCA branch. NIHSS: National Institutes of Health Stroke Scale, ICA: internal carotid artery, BGC: balloon guide catheter, SR: stent retriever, MCA: middle cerebral artery, CVm: Catch View mini, mTICI: Modified Thrombolysis in Cerebral Ischemia score.

Haussen et al. used a method similar to ours in their DT study performed using the Trevo XP ProVue Retriever 3-20 $\mathrm{mm}$ (Stryker Neurovascular, Fremont, California, USA): the "Baby Trevo." They also compressed the proximal part of the thrombus between the microcatheter and the SR to better engage the thrombus and prevent fragmentation. However, to increase the aspiration power and to perform distal aspiration, they exchanged a microcatheter with a 3 Max aspiration catheter with the SR wire, a procedure that they called the "blind exchange with mini-pinning" technique. They used a Trevo 14 microcatheter (0.017-inch) to deploy the SR (8). In our study, we deployed all CVm stents using a 0.013-inch microcatheter. In their study, no patients developed parenchymal hematoma, but they found subarachnoid hemorrhage in three patients. They reported that one of these patients showed active extravasation after proximal occlusion intervention. In our study, one patient developed symptomatic intraparenchymal hematoma, and this patient was the only patient in the study who died. Consistent with the study of Haussen et al. (8), we observed active extravasation in a patient following LVO thrombectomy. The extravasation disappeared in the control image taken after the inflation of the BGC after a few minutes, without the need for additional intervention. A DT procedure was then performed.

Ye et al. conducted a histological analysis of 54 patients to emphasize the risk of secondary embolism events during MT. They divided the patients into two groups, those with and without secondary embolism. Nineteen of 54 patients developed a secondary embolism, and these patients had 
more transient ischemic attacks and strokes than the other group (57.9\% vs $28.6 \%)$. In addition, carotid T was found to be significantly more frequent as the primary occlusion site in the group who developed secondary emboli, and ADAPT was used more frequently in this group (22). In our study, two patients had carotid T occlusion; one was treated with ADAPT and the other with SR.

From a technical point of view, if occlusion in the ICA occurs with tandem occlusion, we first provide intracranial patency and then perform the extracranial procedure, the so-called retrograde approach (21). In this study, the patient who developed active extravasation also had tandem occlusion. In this patient, the BGC could not be navigated distal to the occlusion in the ICA; thus, we had to perform angioplasty first, but we did not perform carotid stenting. In a meta-analysis of 33 studies evaluating the intracranial and extracranial approach in tandem occlusion, no significant difference was found between the two groups in terms of clinical outcomes (21). However, deploying a stent in the ICA would have been problematic in our case, as the requirement for heparinization and antiplatelets would have made it difficult to control extravasation.

Vargas et al. conducted a study of 35 patients using the ADAPT technique in DT. Twenty-eight of the patients had M2, one had A3, and six had tandem occlusion. They used SR as a rescue therapy in $20 \%$ of cases and achieved a $97.1 \%$ rate of successful recanalization. They reported a $59.4 \%$ rate of good clinical outcome at the $90^{\text {th }}$ day and described the aspiration method as safe for distal locations (20). In our study, we preferred to use SR where the occlusion levels were in the third segments. To the best of our knowledge, CVm delivered via a 0.013 -inch microcatheter has the lowest microcatheter profile among the currently available devices.

The low number of patients and retrospective nature were the main limitations of this study. The absence of a control group can also be considered a limitation. However, this study aimed to assess the use and feasibility of the $\mathrm{CVm}$ device in distal thrombectomies. Finally, the data related to recanalization success were retrospectively evaluated by the operators, which may have led to bias in the data analysis.

\section{CONCLUSION}

A potential complication of MT in LVO is distal migration of the thrombus. The distal artery, where the thrombus migrates, can be a highly eloquent territory. DT is important to consider, as $\mathrm{mTICl} 2 \mathrm{c}$ and 3 recanalizations are closely related to better clinical outcomes. Thrombectomy device advances in recent years have served a fundamental role in improving the success and safety of thrombectomy procedures, even in distal vascular territories. Studies with larger patient groups would provide more data, although the outcomes of DT with the combination of $\mathrm{CVm}$ and a 0.013 -inch microcatheter are encouraging.

\section{REFERENCES}

1. Berkhemer OA, Fransen PS, Beumer D, Van Den Berg LA, Lingsma HF, Yoo AJ, Schonewille WJ, Vos JA, Nederkoorn PJ, Wermer MJH, van Walderveen MA, Staals J, et al., for the MR CLEAN Investigators: A randomized trial of intraarterial treatment for acute ischemic stroke. N Engl J Med 372:11-20, 2015

2. Campbell BC, Mitchell PJ, Kleinig TJ, Dewey HM, Churilov L, Yassi N, Yan B, Dowling RJ, Parsons MW, Oxley TJ, Wu TY, Brooks M, Simpson MA, Miteff F, Levi CR, Krause M, Harrington TJ, Faulder KC, Steinfort BS, Priglinger M, Ang T, Scroop R, Barber PA, McGuinness B, Wijeratne T, Phan TG, Chong W, Chandra RV, Bladin CF, Badve M, Rice H, de Villiers L, Ma H, Desmond PM, Donnan GA, Davis SM, et al., for the Extend -IA Investigators: Endovascular therapy for ischemic stroke with perfusion-imaging selection. $\mathrm{N}$ Engl $\mathrm{J}$ Med 372:1009-1018, 2015

3. Costalat V, Lobotesis K, Machi P, Mourand I, Maldonado I, Heroum C, Vendrell JF, Milhaud D, Riquelme C, Bonafe A, Arquizan C: Prognostic factors related to clinical outcome following thrombectomy in ischemic stroke (RECOST study). 50 patients prospective study. Eur J Radiol 81:4075-4082, 2012

4. Del Zoppo GJ, Poeck K, Pessin MS, Wolpert SM, Furlan AJ, Ferbert A, Alberts MJ, Zivin JA, Wechsler L, Busse O, Greenlee R Jr, Brass L, Mohr JP, Feldmann E, Hacke W, Kase CS, Biller J, Gress D, Otis SM: Recombinant tissue plasminogen activator in acute thrombotic and embolic stroke. Annals of Neurology 32:78-86, 1992

5. Fischer ES: Die Lageabweichungen Der vorderen Hirnarterie Im Gefassbild. Munster: Zentralblatt Neurochirurgie, 1938

6. Gascou G, Lobotesis K, Machi P, Maldonado I, Vendrell JF, Riquelme C, Eker O, Mercier G, Mourand I, Arquizan C, Bonafe A, Costalat V: Stent retrievers in acute ischemic stroke: Complications and failures during the perioperative period. Am J Neuroradiol 35:734-740, 2014

7. Goyal M, Demchuk AM, Menon BK, Eesa M, Rempel JL, Thornton J, Roy D, Jovin TG, Willinsky RA, Sapkota BL, Dowlatshahi D, Frei DF, Kamal NR, Montanera WJ, Poppe AY, Ryckborst KJ, Silver FL, Shuaib A, Tampieri D, Williams D, Bang OY, Baxter BW, Burns PA, Choe H, Heo JH, Holmstedt CA, Jankowitz B, Kelly M, Linares G, Mandzia JL, Shankar J, Sohn SI, Swartz RH, Barber PA, Coutts SB, Smith EE, Morrish WF, Weill A, Subramaniam S, Mitha AP, Wong JH, Lowerison MW, Sajobi TT, Hill MD, et al., for the ESCAPE Trial Investigators: Randomized assessment of rapid endovascular treatment of ischemic stroke. N Engl J Med 372:1019-1030, 2015

8. Haussen DC, Al-Bayati AR, Eby B, Ravindran K, Rodrigues GM, Frankel MR, Nogueira RG: Blind exchange with minipinning technique for distal occlusion thrombectomy. J Neurointerv Surg 12:392-395, 2019

9. Jang KM, Nam TK, Ko MJ, Choi HH, Kwon JT, Park SW, Byun JS: Thrombolysis in cerebral infarction grade $2 \mathrm{C}$ or 3 represent a better outcome than $2 \mathrm{~B}$ for endovascular thrombectomy in acute ischemic stroke: A network meta-analysis. World Neurosurg 136:419-439, 2020 
10. Jovin TG, Chamorro A, Cobo E, de Miquel MA, Molina CA, Rovira A, Román LS, Serena J, Abilleira S, Ribó M, Millán M, Urra X, Cardona P, López-Cancio E, Tomasello A, Castaño C, Blasco J, Aja L, Dorado L, Quesada H, Rubiera M, HernandezPérez M, Goyal M, Demchuk AM, von Kummer R, Gallofré M and Dávalos A, et al., for the REVASCAT Trial Investigators: Thrombectomy within 8 hours after symptom onset in ischemic stroke. N Engl J Med 372:2296-2306, 2015

11. Kabbasch C, Möhlenbruch M, Stampfl S, Mpotsaris A, Behme D, Liebig T: First-line lesional aspiration in acute stroke thrombectomy using a novel intermediate catheter: Initial experiences with the SOFIA. Interv Neuroradiol 22:33-39, 2016

12. Kleine JF, Wunderlich S, Zimmer C, Kaesmacher J: Time to redefine success? $\mathrm{TICl} 3$ versus $\mathrm{TICl} 2 \mathrm{~b}$ recanalization in middle cerebral artery occlusion treated with thrombectomy. J Neurointerv Surg 9:117-121, 2017

13. Klinger-Gratz PP, Schroth G, Gralla J, Jung S, Weisstanner C, Verma RK, Mordasini P, Kellner-Weldon F, Hsieh K, Heldner MR, Fischer U, Arnold M, Mattle HP, El-Koussy M: Protected stent retriever thrombectomy prevents iatrogenic emboli in new vascular territories. Neuroradiology 57:1045-1054, 2015

14. Kuybu O, Tadi P, Dossani RH: Posterior Cerebral Artery Stroke. Florida: Stat Pearls, 2019

15. Pereira VM, Gralla J, Davalos A, Bonafé A, Castaño C, Chapot R, Liebeskind DS, Nogueira RG, Arnold M, Sztajzel R, Liebig T, Goyal M, Besselmann M, Moreno A, Schroth G, Alamovitch $S$, Arquizan C, Dohmen C, Killer-Oberpfalzer M, Broussalis E, Krause L, Lopez-Ibor L, Macho J, Amaro S, Menon B, Millàn M, Miteff F, Faulder K, Piotin M, Weber R, Parrilla G: Prospective, multicenter, single-arm study of mechanical thrombectomy using Solitaire Flow Restoration in acute ischemic stroke. Stroke 44:2802-2807, 2013
16. Powers WJ, Derdeyn CP, Biller J, Coffey CS, Hoh BL, Jauch EC, Johnston KC, Johnston SC, Khalessi AA, Kidwell CS, Meschia JF, Ovbiagele B, Yavagal DR: American Heart Association/American Stroke Association focused update of the 2013 guidelines for the early management of patients with acute ischemic stroke regarding endovascular treatment: A guideline for healthcare professionals from the American Heart Association/American Stroke Association. Stroke 46:3020-3035, 2015

17. Quiñones-Hinojosa A: Schmidek and Sweet: Operative Neurosurgical Techniques E-Book. $6^{\text {th }}$ ed. Philadelphia: Elsevier, 2012

18. Rha JH, Saver JL: The impact of recanalization on ischemic stroke outcome: A meta-analysis. Stroke 38:967-973, 2007

19. Saver JL, Goyal M, Bonafe A, Diener H-S, Levy El, Pereira VM, Albers GW, Cognard C, Cohen DJ, Hacke W, Jansen O, Jovin TG, Mattle HP, Nogueira RG, Siddiqui AH, Yavagal DR, Baxter BW, Devlin TG, Lopes DK, Reddy VK, Rochemont RM, Singer OC, Jahan R, et al., for the SWIFT PRIME Investigators: Stentretriever thrombectomy after intravenous t-PA vs t-PA alone in stroke. N Engl J Med 372:2285-2295, 2015

20. Vargas J, Spiotta AM, Fargen K, Turner RD, Chaudry I, Turk A: Experience with a direct aspiration first pass technique (ADAPT) for thrombectomy in distal cerebral artery occlusions causing acute ischemic stroke. World Neurosurg 99:31-36, 2017

21. Yang D, Shi Z, Lin M, Zhou Z, Zi W, Wang H, Hao Y, Guo F, Liu W, Xu G, Xiong Y, Liu X: Endovascular retrograde approach may be a better option for acute tandem occlusions stroke. Interv Neuroradiol 25:194-201, 2019

22. Ye G, Qi P, Chen K, Tan T, Cao R, Chen J, Lu J, Wang D: Risk of secondary embolism events during mechanical thrombectomy for acute ischemic stroke: A single-center study based on histological analysis. Clin Neurol Neurosurg 193:105749, 2020 